J. Lake Sci. (湖泊科学), 2021, 33(3):675-686

DOI 10. 18307/2021. 0305

(c) 2021 by Journal of Lake Sciences

\title{
南水北调中线干渠浮游植物群落时空格局及其决定因子"
}

\author{
张春梅 $^{1,2}$, 朱宇轩 $^{2}$, 宋高飞 ${ }^{2}$, 米武娟 ${ }^{2}$, 毕永红 $^{2 * *}$, 王树䂞 ${ }^{3}$, 梁建奎 $^{3}$, 尚鸣宇 ${ }^{3}$ \\ (1: 大连海洋大学, 大连 116023) \\ (2: 中国科学院水生生物研究所,淡水生态与生物技术国家重点实验室,武汉 430072) \\ (3: 南水北调中线干线工程建设管理局, 北京 100038)
}

\begin{abstract}
摘 要: 为了解南水北调中线干渠浮游植物群落的时空格局, 自 2018 年 8 月开始分 4 个季度对干渠沿程的 11 个样点进 行采样调查, 同步开展水环境调查; 共检出浮游植物 7 门 83 属 145 种, 物种丰富度上, 硅藻种类数最多, 绿藻和蓝藻分别 占第 2 和第 3 位, 且春季>秋季>冬季>夏季; 优势种包括极小曲丝藻 (Achnanthidum minutissimum)、桥弯藻 (Cymbella sp.)、 空星藻 (Coelastrum sphaericum) 、衣藻 (Chlamydomonas sp.) 等( 优势度 $Y>0.02$ ) ; 全年叶绿素 $a$ 浓度为 $(4.09 \pm 2.89) \mu \mathrm{g} / \mathrm{L}$, 细胞密度为 $(6.79 \pm 7.15) \times 10^{6} \mathrm{cells} / \mathrm{L}$, 夏季细胞密度显著高于其他季节, 以绿藻、蓝藻为主, 其他季节以硅藻、绿藻为主; 空间上,细胞密度从南到北呈递增趋势,穿黄工程后显著高于穿黄工程前; RDA 与多元线性回归分析显示: 水温和营养盐 是影响群落结构的关键因素, 其次是流量和流速,这些因子成为群落时空格局的决定因子; NMDS 与聚类分析显示: 时间 变化对于群落结构产生的影响比空间变化更为显著. 本研究确认了跨流域长距离输水的中线干渠中浮游植物群落的显 著时空异质性; 鉴于流速、流量对群落的决定作用, 建议在输水管理中加强生态调度技术研究, 以调控浮游植物群落, 保 障水质稳定.
\end{abstract}

关键词: 南水北调中线; 浮游植物; 群落结构; 环境因子

\section{Spatiotemporal pattern of phytoplankton community structure and its determining factors in the channel of the middle route of South-to-North Water Diversion Project*}

\author{
Zhang Chunmei ${ }^{1,2}$, Zhu Yuxuan ${ }^{2}$, Song Gaofei $^{2}$, Mi Wujuan ${ }^{2}$, Bi Yonghong ${ }^{2 * *}$, Wang Shulei ${ }^{3}$, Liang Jiankui ${ }^{3} \&$ \\ Shang Mingyu ${ }^{3}$ \\ (1: University of Dalian Ocean, Dalian 116023, P.R.China) \\ ( 2: State Key Laboratory of Fresh Water Ecology and Biotechnology, Institute of Hydrobiology, Chinese Academy of Sciences, \\ Wuhan 430072, P.R.China) \\ (3: Management Bureau of South to North Water Transfer Canal Project, Beijing100038, P.R.China)
}

Abstract: In order to investigate the spatiotemporal pattern of phytoplankton communities and the determining factors in the channel of the Middle Route of South-to-North Water Diversion Project, seasonal samples of phytoplankton and aquatic from 11 different sample stations were collected and analyzed from 2018 to 2019. Phytoplankton species were detected as 7 Phylum, 145 species, with the largest number of taxa belonging to Bacillariophyta. The dominant taxa were Achnanthidum minutissimum, Cymbella sp., Coelastrum sphaericum, Chlamydomonas sp., etc. $(Y>0.02)$. The chlorophyll-a concentration was $(4.09 \pm 2.89) \mu g / \mathrm{L}$, and the cell density was $(6.79 \pm 7.15) \times 10^{6}$ cells $/ \mathrm{L}$, with the maximum cell density in summer. Chlorophyta was dominant in summer, but Bacillariophyta were prevalent in other seasons. There existed a gradually increase in chlorophyll- $a$ concentration and cell density along the channel, and there were significant differences before and after the Yellow River Tunnel Project; Meanwhile, the results of redundancy and multiple linear regression analysis for the relationship between the phytoplankton and environment showed that water temperature and nutrient were the key factors, and the second was water flow and water velocity; NMDS and cluster analysis in-

* 2020-07-06 收稿;2020-08-27 收修改稿.

国家水体污染控制与治理科技重大专项(2017ZX07108-001) 资助.

** 通信作者;E-mail:biyh@ ihb.ac.cn. 
dicated the phytoplankton community-owned obvious spatiotemporal heterogeneity in the long-distance water transportation, and the seasonal changes showed much more pronounced effect on the phytoplankton community compositions than spatial variation. In view of the determining role of flow rate and flow velocity on phytoplankton structure, more attention should be paid to the ecological scheduling regulation of phytoplankton community in the management of water quality safety and stability.

Keywords: Middle route of South-North Water Diversion Project; phytoplankton; community structure; environment factors

浮游植物是水域生态系统中的初级生产者和基础环节, 能对水体生态环境的变化做出快速直接的响 应, 生态环境变化也会直接或者间接影响浮游植物的群落结构 ${ }^{[1]}$; 一般认为, 浮游植物种类数量的变化以及 时空格局是营养盐、温度、光照、水动力条件等时空变化的结果 ${ }^{[2-4]}$. 近年来, 对于浮游植物群落结构的时空 演变过程和关键影响因子的相关报道较多, 丹江口水库不同区域的浮游植物优势群在同一季节具有显著差 异, 且随着季节变化其群落结构的演变趋势也有所不同 ${ }^{[5]}$. 三峡水库的调查表明浮游植物具有明显的季节 演变和空间差异 ${ }^{[6]}$. 不同水体浮游植物群落结构特征不同, 浮游植物因其对不同水环境的敏感响应和特异 适应性而成为水环境监测的重要生物指示物种.

南水北调中线工程解决了河南、河北、北京、天津 4 个省市的水资源短缺问题,具有重要的战略意义,发 挥了巨大效益. 中线干渠为混凝土硬化渠道, 与沿岸河流不交叉,水体特性不同于湖泊、河流和水库等自然 水体, 是一个全新封闭的人工系统 ${ }^{[7]}$. 全面通水以来, 在营养盐、水文水动力条件和生态因子的作用下, 浮游 植物群落结构处于动态演变过程中, 特定时段还出现过某一特定类群生物量快速增殖的现象, 成为影响输 水水质的潜在生态问题. 2005 年对中线工程水源地的研究 ${ }^{[8]}$ 表明, 陶岔渠首处无论在种类与数量上硅藻均 占据绝对优势, 春、秋季硅藻和绿藻较多, 夏季蓝藻较为丰富. 2017 年对中线工程水源地的研究 ${ }^{[9]}$ 表明, 群落 演替由春季的硅藻、蓝藻向夏季的硅藻、蓝藻和隐藻以及秋、冬季的硅藻、隐藻和蓝藻转变. 尽管南水北调中

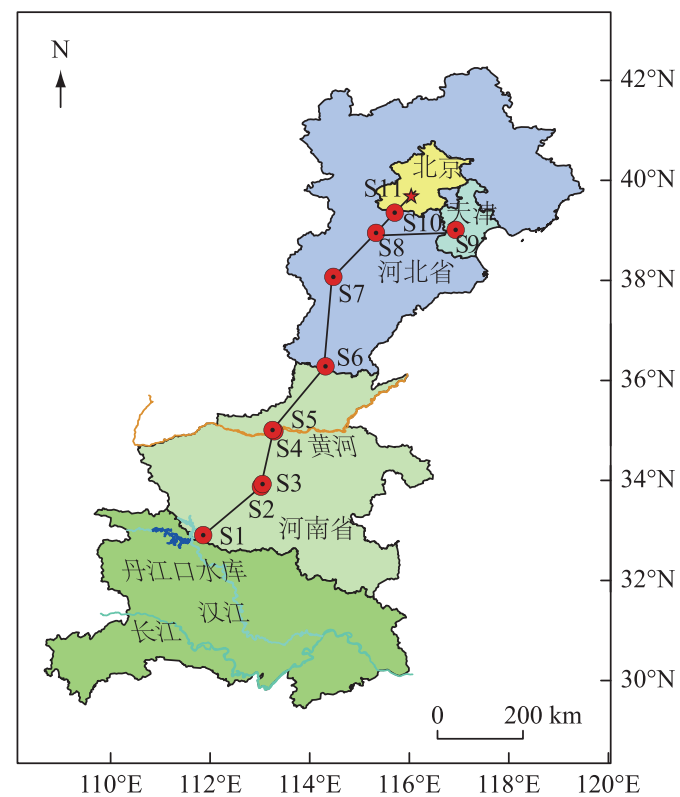

图 1 南水北调中线干渠沿程采样点分布 (S1 陶岔渠首、S2 沙河渡槽进口、S3 鲁山落地槽、 S4 穿黄工程南岸、S5 穿黄工程北岸、S6 漳河北、 S7 古运河暗渠、S8 西黑山进口闸、S9 天津外环河、 S10 惠南庄北拒马河、S11 团城湖）

Fig. 1 Distribution of sampling sites along the main channel of the middle route of South-to-North Water Diversion Project 线工程水源地浮游植物有一些相关研究报道, 但迄今 为止针对南水北调中线干渠水体浮游植物群落结构 的研究资料较为鿒乏.

鉴于中线干渠独特的渠道结构、较低的营养水平 以及持续扰动掺混的流动状况, 与丹江口水库来水中 浮游植物的生境不同, 因此本研究开展浮游植物群落 结构与环境因子的同步调查, 主要目的是验证以下假 设: 在跨流域长距离输水过程中浮游植物不仅仅是随 水流的被动运输, 可能存在沿程增殖生长行为; 且浮 游植物群落结构的时空异质性是由多因子共同决定 的. 通过揭示干渠浮游植物群落结构特征及其演变 的关键驱动因子, 为深人理解南水北调中线干渠输水 系统及其科学运行管理提供支撑.

\section{1 材料与方法}

\section{1 研究区域与采样方法}

南水北调中线干渠 $\left(32.68^{\circ} \sim 39.99^{\circ} \mathrm{N}, 111.72^{\circ} \sim\right.$ $116.27^{\circ} \mathrm{E}$ ) 全长 $1432 \mathrm{~km}$, 多年平均调水量 95 亿 $\mathrm{m}^{3}$, 属于长距离跨气候带调水工程, 南北纵跨 8 个纬度, 四季气温变化分明. 本研究采样时间为 2018 年 8 月一 2019 年 5 月,按照夏季、秋季、冬季、春季每个季度月 末采集一次, 共计 4 次采样. 自河南南阳市淅川县陶 岔渠首开始, 到北京市团城湖共设置 11 个采样点 (图 1). 


\section{2 样品采集与处理}

现场测定表层水温 (WT)、 $\mathrm{pH}$ 、流速 $(\mathrm{Vel}) 、$ 、浊度 ( Tur)、透明度 (SD)、流量 (Flow) 和溶解氧 ( DO). 实验 室测定表层水体的理化性质: 叶绿素 $a($ Chl. $a$ ) 浓度使用 $90 \%$ 丙酮提取, 总氮 (TN) 浓度采用过硫酸钾氧化法 测定, 总磷 ( TP ) 浓度采用过硫酸钾消解法测定, 磷酸盐 $\left(\mathrm{PO}_{4}^{3-}-\mathrm{P}\right)$ 浓度采用钿锑抗分光光度法测定, 硝态氮 $\left(\mathrm{NO}_{3}^{-}-\mathrm{N}\right)$ 浓度采用紫外分光光度法测定, 氨氮 $\left(\mathrm{NH}_{3}-\mathrm{N}\right)$ 浓度采用纳氏试剂分光光度法测定, 高锰酸盐指数 $\left(\mathrm{COD}_{\mathrm{Mn}}\right)$ 采用高镇酸钾消解滴定法测定 ${ }^{[10]}$.

使用 $25^{\#}$ 浮游生物网采集定性样品, 用适量 $4 \%$ 甲醛固定, 定量样品用 $5 \mathrm{~L}$ 玻璃采样器取表层水样置于 瓶中, 加人 $1 \%$ 鲁哥氏液现场固定, 样品静置 $48 \mathrm{~h}$, 沉降并浓缩至 $30 \mathrm{~mL}$, 充分摇匀后吸取 $0.1 \mathrm{~mL}$ 至浮游生物 计数框, 在 Olympus CX23 下进行计数 ${ }^{[11]}$. 藻类鉴定方法参照文献 [12].

\section{3 数据处理}

优势度计算公式为:

$$
Y=\frac{n_{i}}{N} f_{i}
$$

式中, $N$ 表示同一样品中浮游藻类总个体数, $n_{i}$ 表示第 $i$ 种浮游藻类个体数, $Y$ 表示优势度, $f_{i}$ 表示第 $i$ 种浮游 植物在样品中出现的频度, $Y>0.02$ 的物种定义为优势种 ${ }^{[13]}$.

图形绘制在 Graphad prism 8 软件中完成, 采用 ArcGIS 10.2 软件作为空间分析工具, 对沿线干渠各采样 点浮游植物群落结构特征及细胞密度进行时空格局分析, 应用 IBM SPSS Statistics 25 软件进行方差及相关 性分析,采用Wilcoxon 秩和检验方法检验不同季节穿黄工程前后细胞密度的差异性,使用 $\mathrm{R}$ “vegan”包进行 非度量多维尺度 NMDS 与 ANOSIM 差异性分析, 使用 R “UpSet” 包中 Upset 函数进行样点间共有物种的维恩 图分析.

采用 Canoco 4.5 软件 ${ }^{[14]}$ 对物种数据与环境因子数据进行排序分析, 通过对物种数据去趋势对应分析 (DCA) 确定排序模型, 环境变量解释显著性由 Monte Carlo 测试检验, $P$ 值小于 0.05 则可用此方法进行检验 排序, 特征值越大, 环境因子对藻类结构的影响越大, $P$ 值越小, 相关性越显著, 结果用物种一环境因子关系 的双序图表示.

\section{2 结果}

\section{1 浮游植物群落特征}

2.1.1 物种组成与优势种 调查期间共鉴定到浮游植物 7 门 83 属 145 种, 以硅藻为主, 共有 68 种, 占总种类 数的比例为 $46.89 \%$; 其次为绿藻, 有 47 种, 所占比例为 $32.41 \%$; 蓝藻 16 种, 所占比例为 $11.03 \%$; 隐藻、裸藻、 金藻、甲藻种类较少,所占比例分别为 $3.45 \% 、 0.27 \% 、 0.27 \%$ 和 $0.68 \%$.

从季节上看, 浮游植物种类数排序为春季 $>$ 秋季 $>$ 冬季 $>$ 夏季. 夏季绿藻种类最多, 硅藻、蓝藻次之, 其他季 节种类数排序为硅藻 $>$ 绿藻 $>$ 蓝藻. 空间上陶岔渠首处 $(\mathrm{S} 1)$ 物种数最低, 从南到北呈递增趋势, 沿程各样点均存 在硅藻, 且物种数呈现先增加后降低的波动性变化, 以陶忿渠首处最低,穿黄工程北岸 (S5) 最高 (图 2).

多集合维恩图 (图 3) 显示, 各样点浮游植物的共有种类有 19 种, 主要为硅藻, 包括桥弯藻 (Cymbella sp.)、极小曲丝藻 (Achnanthidum minutissimum) 、内丝藻 (Encyonopsis sp.)、小环藻 (Cyclotella sp.)、针杆藻 (Synedra sp.) 等. 蓝藻主要为束丝藻 (Aphanizomenon sp.)、微囊藻 (Microcystis sp.)、假鱼腥藻 (Pseudanabaena sp.), 隐藻主要为隐藻 (Cryptomonas sp.)、斜结隐藻 (Plagioselmis sp.). 陶岔处物种数目最少, 穿黄北物种数 目最多. 相比较于陶岔渠首处的物种种类, 其他样点共有的新增加物种有 4 种, 为空星藻 (Coelastrum sphaericum)、维里纳优美藻 (Delicata verena) 、单角盘星藻具孔变种 (Pediastrum simplex var. duodenarium) 及瞳孔舟 形藻 ( Navicula pupula). 各样点特有物种数分别为 $2 、 2 、 2 、 3 、 6 、 1 、 1 、 1 、 3 、 1 、 1$ 种, 特有物种较少, 沿程物种变 化较小.

浮游植物优势种共 19 种 (表 1 ), 不同季节优势类群存在差异: 夏季以硅藻、绿藻、蓝藻为优势类群, 空星 藻优势度最大. 秋、冬、春季以硅藻、绿藻、蓝藻、隐藻为优势类群, 分别以针杆藻、尖针杆藻 (Synedra acus)、桥 弯藻、斜结隐藻占据较大优势. 桥弯藻和极小曲丝藻为全年优势种. 


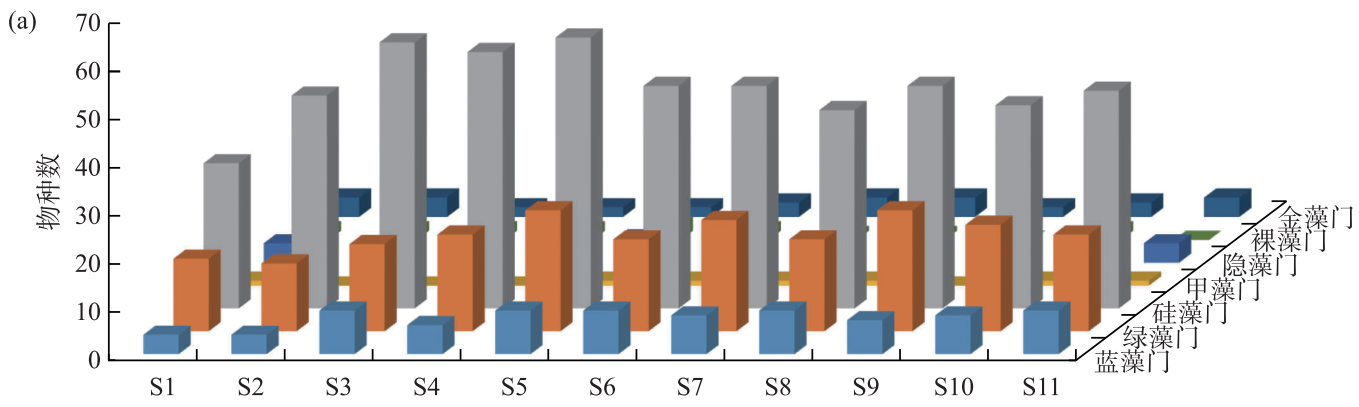

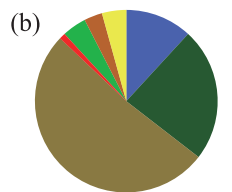

春季 $($ 物种 $=93)$

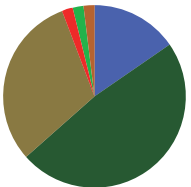

夏季 $($ 物种 $=52)$

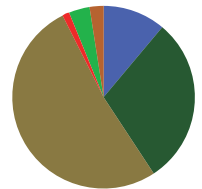

秋季 $($ 物种 $=81)$

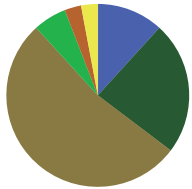

冬季 $($ 物种 $=68)$

蓝藻门口绿藻门口硅藻门口隐藻门口裸藻门口甲藻门口金藻门

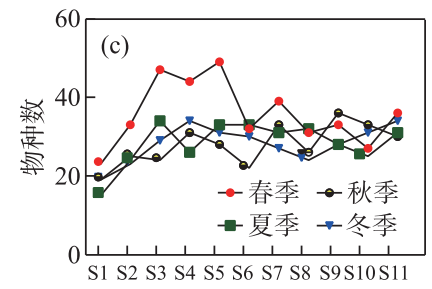

图 2 物种组成分布示意图: (a) 空间分布; (b) 各季节门水平变化; (c) 各季节空间分布

Fig.2 Distribution proportion of species: (a) spatial distribution; (b) species on phylum level varies from seasons; (c) spatial distribution varies from seasons

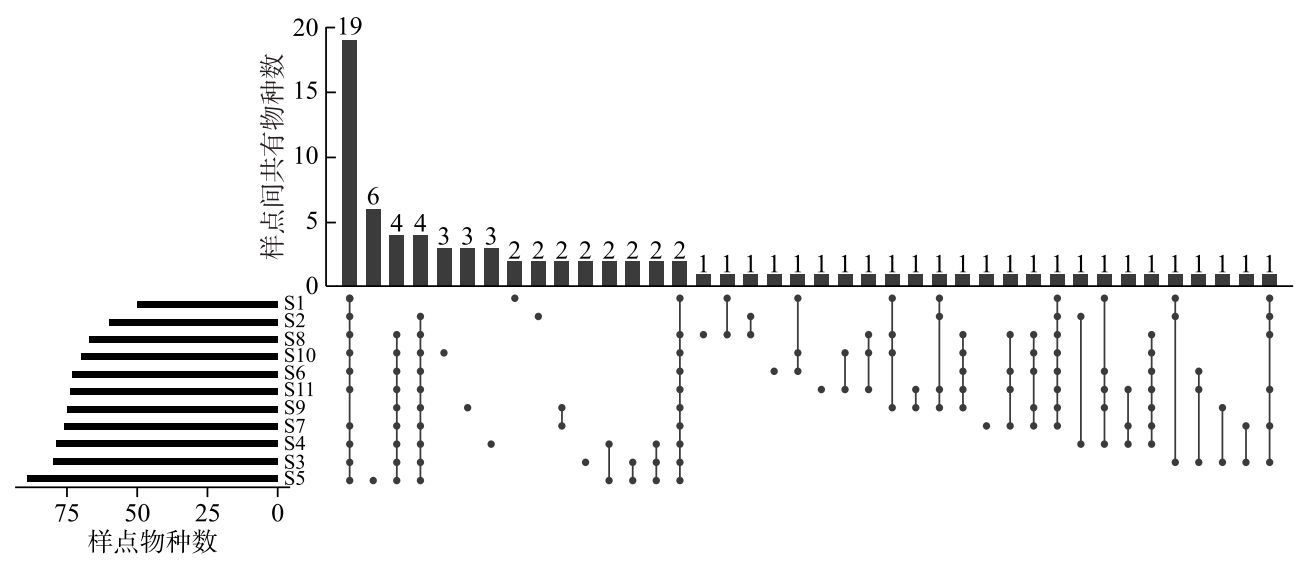

图 3 样点间浮游植物种类多集合维恩图(黑色点表示该位置有数据,点线图表示样点间存在交集， 柱状图上的数字表示样点间的共有物种数,左边柱形图表示各样点的物种数)

Fig.3 Multi-set venn diagram of phytoplankton species between sampling sites( Black dots indicated the existence of data at the sites, the dot plots indicated the intersection of the different sites, the numbers on the bar chart indicate the number of species in common between different sites, the bar chart on the left showed the number of species at each site)

2.1 .2 群落的时空格局 不同季节浮游植物群落组成存在一定差异 (图 4), 细胞密度主要是由硅藻、绿藻、蓝 藻贡献, 硅藻在全年占据优势. 春季以硅藻为主, 其相对丰度沿程递增, 隐藻、金藻主要出现在渠首 (S1). 夏 季绿藻相对丰度较高, 蓝藻、硅藻次之, 隐藻主要出现在渠首 $(\mathrm{S} 1)$, 穿黄工程前 $(\mathrm{S} 1 \sim \mathrm{S} 3)$ 与穿黄工程后 ( S5 S11) 均以硅藻、绿藻为主, 但所占比例存在差异. 秋、冬季为硅藻 $>$ 绿藻 $>$ 蓝藻, 与夏季相比, 蓝藻比例下降, 隐 藻的相对丰度在穿黄工程前各样点增加, 冬季硅藻与绿藻相对丰度沿程大体呈相反的变化. 陶岔渠首处以 硅藻、绿藻、隐藻及蓝藻为主要优势类群, 冬季蓝藻所占比例较小. 
表 1 南水北调中线干渠浮游植物优势种及优势度

Tab.1 Dominant species and dominance of the phytoplankton in the main channel of the middle route of South-to-North Water Diversion Project

\begin{tabular}{|c|c|c|c|c|c|}
\hline 门 & 优势种 & 夏季 & 秋季 & 冬季 & 春季 \\
\hline \multirow[t]{7}{*}{ 硅藻门 } & 桥弯藻 Cymbella sp. & 0.055 & 0.090 & 0.064 & 0.090 \\
\hline & 舟形藻 Navicula sp. & 0.020 & - & - & - \\
\hline & 极小曲丝藻 Achnanthidum minutissimum & 0.024 & 0.027 & 0.056 & 0.060 \\
\hline & 针杆藻 Synedra sp. & - & 0.140 & - & - \\
\hline & 杂拟内丝藻 Encyonopsis descripta & - & - & - & 0.066 \\
\hline & 具碟星藻 Discostella stelligera & - & - & - & 0.022 \\
\hline & 尖针杆藻 Synedra acus & - & - & 0.104 & 0.042 \\
\hline \multirow[t]{5}{*}{ 绿藻门 } & 空星藻 Coelastrum sphaericum & 0.133 & 0.054 & - & - \\
\hline & 衣藻 Chlamydomonas sp. & 0.094 & - & 0.103 & 0.029 \\
\hline & 栅藻 Scenedesmus sp. & 0.065 & - & - & - \\
\hline & $\begin{array}{c}\text { 单角盘星藻具孔变种 Pediastrum simplex } \\
\text { var. duodenarium }\end{array}$ & 0.036 & 0.042 & - & - \\
\hline & 小球藻 Chlorella sp. & - & - & 0.038 & - \\
\hline \multirow[t]{5}{*}{ 蓝藻门 } & 微囊藻 Microcystis sp. & 0.101 & 0.042 & - & 0.089 \\
\hline & 隐球藻 Aphanocapsa sp. & 0.055 & - & - & - \\
\hline & 假鱼腥藻 Pseudanabaena sp. & 0.055 & - & - & 0.047 \\
\hline & 平裂藻 Merismopedia sp. & 0.028 & - & - & - \\
\hline & 束丝藻 Aphanizomenon sp. & - & - & 0.064 & - \\
\hline \multirow[t]{2}{*}{ 隐藻门 } & 隐藻 Cryptomonas sp. & - & 0.050 & - & - \\
\hline & 斜结隐藻 Plagioselmis sp. & - & - & 0.090 & 0.021 \\
\hline
\end{tabular}

一表示优势度 $Y<0.02$.

2.1 .3 细胞密度与叶绿素 $a$ 浓度 浮游植物细胞密度的季节变化范围为 $2.16 \times 10^{6} \sim 1.92 \times 10^{7}$ cells $/ \mathrm{L}$, 平均密 度为 $(6.79 \pm 7.15) \times 10^{6} \mathrm{cells} / \mathrm{L}$, 其中夏季 $>$ 春季 $>$ 秋季 $>$ 冬季, 单因素方差分析显示夏季显著高于其他季节 $(P<0.05$ ), 其他各季节间无显著差异 (图 5a). 从空间尺度上分析, 沿程各样点浮游植物细胞密度呈现先增 加后降低、再增加再降低的“M” 型变化趋势, 穿黄工程南北 (S4 S5) 与古运河暗渠 (S7) 处均有较高值, 春、 夏季穿黄工程后显著高于穿黄工程前,夏、秋季古运河暗渠处均存在峰值 (图 $5 \mathrm{~b}$ ).

Chl. $a$ 浓度变化范围为 $1.09 \sim 8.85 \mu \mathrm{g} / \mathrm{L}$, 平均值为 $(4.09 \pm 2.89) \mu \mathrm{g} / \mathrm{L}$, 其中夏季 $>$ 秋季 $>$ 春季 $>$ 冬季, 单因 素方差分析显示夏季显著高于其他季节,与细胞密度变化趋势一致 ( 图 5a).

\section{2 环境因子}

调查期间南水北调中线干渠水温为 $5.10 \sim 34.30^{\circ} \mathrm{C}$, 流速为 $0.10 \sim 2.40 \mathrm{~m} / \mathrm{s}, \mathrm{NO}_{3}^{-}-\mathrm{N}$ 浓度为 $0.16 \sim 1.70$ $\mathrm{mg} / \mathrm{L}, \mathrm{NH}_{3}-\mathrm{N}$ 浓度为 $0 \sim 0.14 \mathrm{mg} / \mathrm{L}$, TP 浓度为 $0.00 \sim 0.08 \mathrm{mg} / \mathrm{L}$, 瞬时流量为 $1.77 \sim 322.93 \mathrm{~m}^{3} / \mathrm{s}$ (表 2 ), 其中 $\mathrm{TN}$ 浓度和水温在各季节间存在极显著差异, 春季流速、 $\mathrm{TP}$ 和 $\mathrm{NO}_{3}^{-}-\mathrm{N}$ 浓度与其他季节存在显著差异.

\section{3 群落结构与环境因子的关系}

环境因子与样点的 RDA 分析结果显示(图 6), 前两个排序轴累计解释了 $54.60 \%$ 的物种变异和 $74 \%$ 累 计解释方差. 所有样本按照季节排序, 分为春季、夏季、秋季、冬季. 确认水温和营养盐是影响浮游植物的主 要因子,其次是流量和浊度.

对主要优势类群蓝藻、绿藻与硅藻进行多元线性分析 (表 3) 可知, 硅藻相对丰度与水温呈显著负相关, 绿藻的相对丰度与水温呈显著正相关, 蓝藻细胞密度与流速呈显著负相关, 绿藻与硅藻的细胞密度与 $\mathrm{NH}_{3}-\mathrm{N}$ 浓度、流量呈显著负相关. 

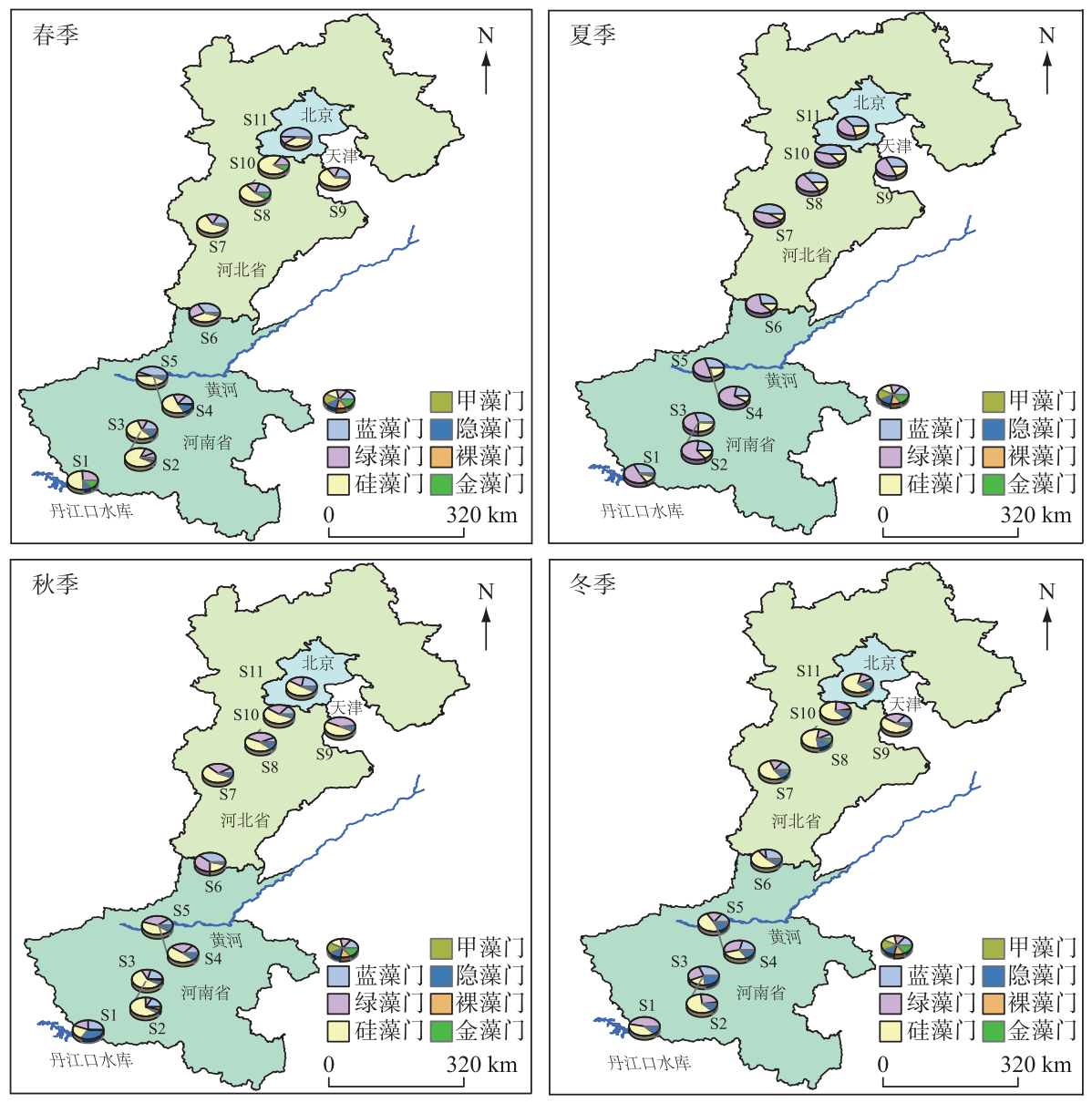

图 4 不同季节各采样点浮游植物群落结构组成

Fig.4 Phytoplankton population structure composition at each sampling site of different seasons

表 2 南水北调中线干渠全年水环境因子平均值

Tab.2 Average of aquatic environmental factors in the main channel of the middle route of South-to-North Water Diversion Project

\begin{tabular}{lcccc}
\hline 参数 & 夏季 & 秋季 & 冬季 & 春季 \\
\hline $\mathrm{TP} /(\mathrm{mg} / \mathrm{L})$ & $0.012 \pm 0.006$ & $0.012 \pm 0.003$ & $0.011 \pm 0.016$ & $0.063 \pm 0.006$ \\
$\mathrm{PO}_{4}^{3-}-\mathrm{P} /(\mathrm{mg} / \mathrm{L})$ & $0.009 \pm 0.003$ & $0.007 \pm 0.002$ & $0.024 \pm 0.041$ & $0.108 \pm 0.172$ \\
$\mathrm{TN} /(\mathrm{mg} / \mathrm{L})$ & $1.493 \pm 0.190$ & $0.648 \pm 0.190$ & $1.016 \pm 0.013$ & $1.786 \pm 0.124$ \\
$\mathrm{NH}_{3}-\mathrm{N} /(\mathrm{mg} / \mathrm{L})$ & $0.054 \pm 0.026$ & $0.099 \pm 0.021$ & $0.016 \pm 0.013$ & $0.104 \pm 0.022$ \\
$\mathrm{NO}_{3}^{-}-\mathrm{N} /(\mathrm{mg} / \mathrm{L})$ & $0.927 \pm 0.098$ & $0.162 \pm 0.004$ & $0.096 \pm 0.026$ & $1.418 \pm 0.091$ \\
$\mathrm{COD}_{\mathrm{Mn}} /(\mathrm{mg} / \mathrm{L})$ & $2.840 \pm 0.395$ & $2.043 \pm 0.445$ & $1.022 \pm 0.145$ & $2.684 \pm 0.340$ \\
$\mathrm{WT} /{ }^{\circ} \mathrm{C}$ & $30.355 \pm 2.356$ & $15.781 \pm 1.287$ & $6.791 \pm 1.064$ & $22.291 \pm 0.590$ \\
$\mathrm{pH}$ & $8.477 \pm 0.396$ & $8.282 \pm 0.057$ & $8.696 \pm 0.060$ & $8.763 \pm 0.241$ \\
$\mathrm{DO} /(\mathrm{mg} / \mathrm{L})$ & $8.196 \pm 1.412$ & $10.145 \pm 0.899$ & $14.000 \pm 1.799$ & $9.496 \pm 0.587$ \\
$\mathrm{Tur} / \mathrm{m}$ & $1.764 \pm 1.015$ & $6.325 \pm 7.287$ & $1.582 \pm 0.891$ & $7.582 \pm 4.825$ \\
$\mathrm{SD} / \mathrm{m}$ & $2.764 \pm 1.008$ & $2.764 \pm 1.838$ & $4.100 \pm 1.064$ & $1.927 \pm 1.590$ \\
$\mathrm{Flow} /(\mathrm{m} / \mathrm{s})$ & $113.609 \pm 70.946$ & $152.036 \pm 97.184$ & $78.176 \pm 49.259$ & $159.329 \pm 104.440$ \\
$\mathrm{Vel} /(\mathrm{m} / \mathrm{s})$ & $0.790 \pm 0.221$ & $0.940 \pm 0.333$ & $0.499 \pm 0.202$ & $1.627 \pm 0.526$ \\
\hline
\end{tabular}



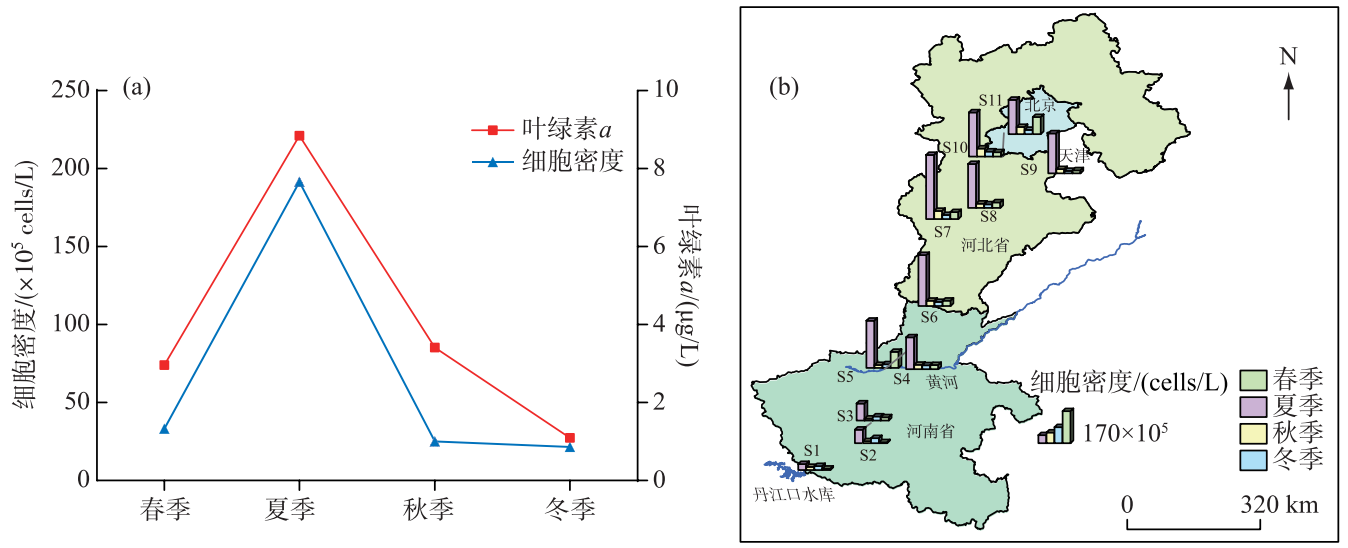

图 5 浮游植物细胞密度与叶绿素 $a$ 浓度的时空格局

Fig.5 Spatial and temporal changes of phytoplankton cell density and chlorophyll-a concentration

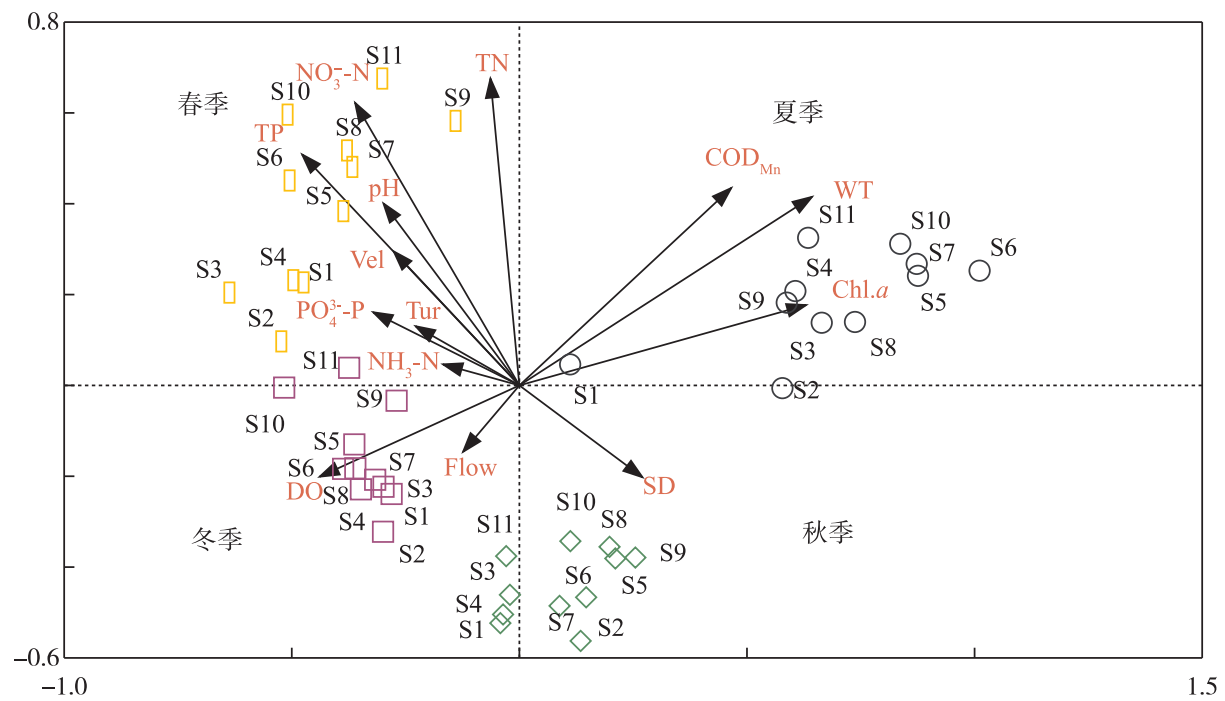

图 6 样方与环境因子的 RDA 二维排序图

Fig.6 Biplot diagram for RDA of the relationship between environment variable and sample sites

表 3 多元线性回归分析

Tab.3 The multiple linear regression analysis $(P<0.05)$

\begin{tabular}{cc}
\hline 密度 $(\lg (x+1))$ & $R^{2}$ \\
\hline 硅藻 $=0.669 \mathrm{COD}_{\mathrm{Mn}}-0.301 \mathrm{Flow}-0.48 \mathrm{NH}_{3}-\mathrm{N}+0.242 \mathrm{Tur}+5.873$ & 0.619 \\
蓝藻 $=0.527 \mathrm{WT}-0.362 \mathrm{Vel}+4.796$ & 0.268 \\
绿藻 $=0.892 \mathrm{WT}-0.335 \mathrm{NH}_{3}-\mathrm{N}-0.125 \mathrm{NO}_{3}^{-}-\mathrm{N}-0.307 \mathrm{Flow}-0.277 \mathrm{TP}$ & 0.846 \\
\hline 相对丰度 $\%$ & $R^{2}$ \\
\hline 硅藻 $=-0.697 \mathrm{WT}+0.5677 \mathrm{TP}+0.597$ & 0.628 \\
蓝藻 $=0.697 \mathrm{COD} \mathrm{Mn}_{-0.321 \mathrm{NH}_{3}-\mathrm{N}}-0.364$ \\
绿藻 $=0.699 \mathrm{WT}-0.381 \mathrm{TP}-0.349 \mathrm{NH}_{3}-\mathrm{N}-0.233 \mathrm{pH}$ & 0.712
\end{tabular}




\section{4 时空异质性}

NMDS 分析显示所有样本按照季节分为 4 组(图 7a), 有明显的季节变化. ANOSIM 结果显示 (图 7b) 组 间差异显著大于组内 $(P<0.01, R=0.767)$, 即浮游植物群落结构组成在时间上的差异显著大于空间上的差 异,且不同季节间两两比较均存在显著差异 $(P<0.01)$.

基于 UPGMA 算法构建聚类树状结构, 结果如图 8 所示: 距离相近的样点群落组成相似性较高, 渠首处 (S1) 与相邻样点间群落相似性较低. 穿黄工程前 $(\mathrm{S} 1 \sim \mathrm{S} 3)$ 与穿黄工程后 $(\mathrm{S} 5 \sim \mathrm{S} 11)$ 可大致分为两组, Wilcoxon 秩和检验显示: 春季穿黄工程前与穿黄工程后的绿藻、硅藻的细胞密度存在显著差异 $(P<0.05)$, 穿 黄工程后显著高于穿黄工程前, 夏季穿黄工程后的蓝藻、绿藻、硅藻细胞密度均显著高于穿黄前. 秋季穿黄 后的硅藻细胞密度显著高于穿黄前. 冬季绿藻、金藻的细胞浓度存在显著差异.
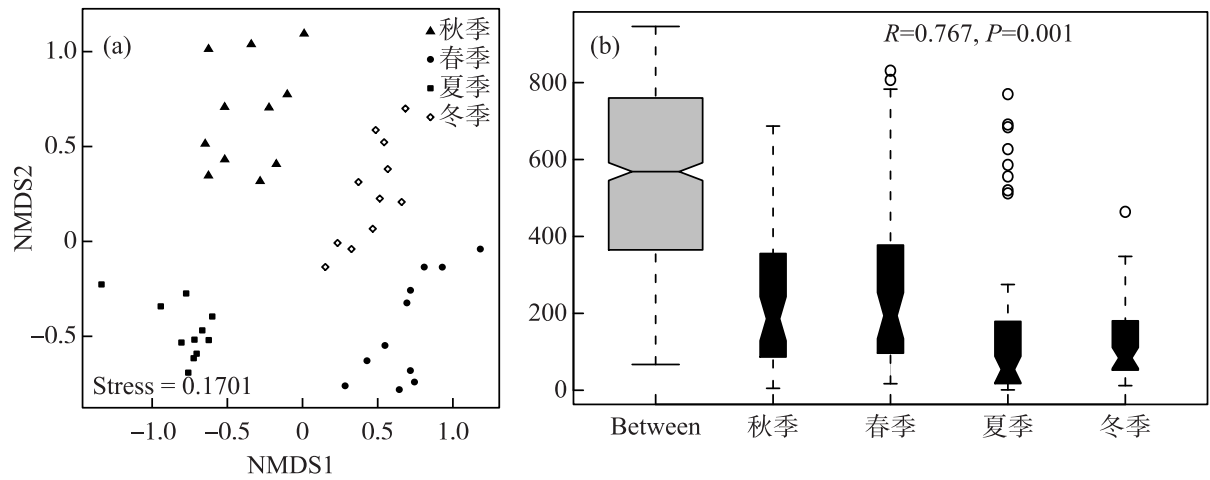

图 7 浮游植物群落组成的时间变异分析: (a) NMDS ; (b) ANOSIM

Fig.7 Temporal variability analysis of phytoplankton community composition: (a) NMDS; (b) ANOSIM

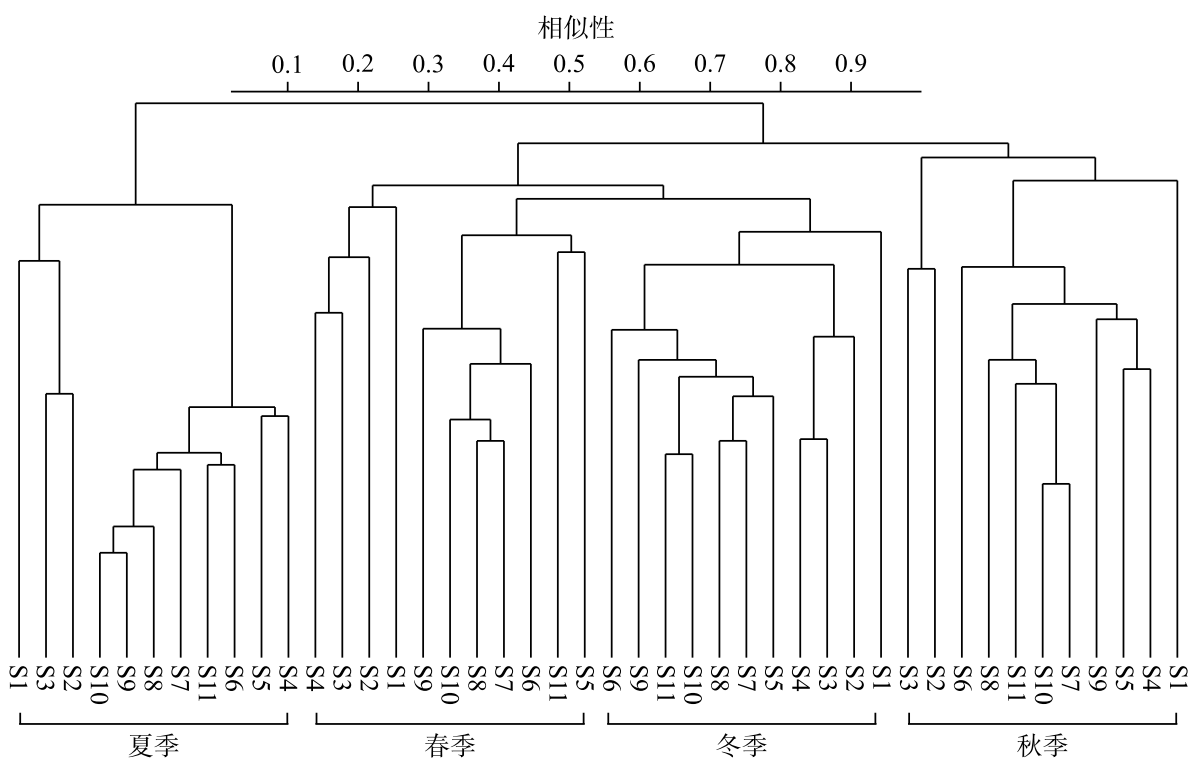

图 8 基于 Bray-curtis 距离矩阵的聚类样点图

Fig. 8 Bray-curtis dissimilarity based on distance matrix showing the clustering of sampling sites 


\section{3 讨论}

\section{1 浮游植物群落结构及其演变}

浮游植物季节演变的一般规律为: 春、秋季以喜低温的硅藻、金藻为主, 夏季以喜高温的蓝藻 ${ }^{[15]}$ 和绿藻 为主, 冬季藻类种类与数量都相对较少 ${ }^{[12]}$. 千岛湖 ${ }^{[16]}$ 冬、春季浮游植物主要类群为硅藻、隐藻, 夏季为绿藻、 硅藻, 秋季为蓝藻、绿藻和硅藻. 富春江水库 ${ }^{[17]}$ 春季绿藻、隐藻、硅藻占优, 夏季蓝藻及硅藻占优, 秋季硅藻 和隐藻占据较大优势. 中线干渠浮游植物群落季节变化与千岛湖及富春江类似, 全年以硅藻为主, 春季为硅 藻型, 夏季为绿藻一蓝藻一硅藻型, 秋、冬季为硅藻一绿藻一蓝藻型. 这些水体均属于清洁水体, 群落特征与水 体类型具有明显的对应关系. 另外, 不同水体的浮游植物群落因环境过滤作用而显示明显的差异, 黑河张掖 段的上游营养水平较低, 主要优势类群为普生性的硅藻清洁指示种, 下游营养水平较高, 主要优势类群为 蓝、绿藻中的中一富营养型指示种 ${ }^{[18]}$. 广州地表水浮游植物的演变显示, 休耕期间营养水平较低, 硅藻为主 要优势类群, 播种期间营养水平高, 蓝、绿藻取代硅藻成为主要优势类群 ${ }^{[19]}$. 中线干渠全年水质较好, 所有 断面均可达到 II 类及以上标准, 营养水平为贫一中营养型, 硅藻种类最多, 为 68 种, 春、秋、冬季均以硅藻种 类为主要类群,这种以硅藻为主的浮游植物群落是水体营养水平较低的特征之一.

空间上, 相邻样点的群落组成具有一定的相似性. 虽然本研究结果中陶岔渠首处 TN 浓度为 $0.69 \sim 1.76$ $\mathrm{mg} / \mathrm{L}, \mathrm{TP}$ 浓度为 $0 \sim 0.06 \mathrm{mg} / \mathrm{L}$, 比前人的研究 ${ }^{[8-9]}$ 氮、磷浓度增加, 但陶岔渠首样点浮游植物的群落结构与 演变的过程与丹江口水库仍具有高度的相似性, 说明相较于水体条件的变化, 陶岔渠首处的浮游植物群落 受到丹江口水库水源补给的影响更显著. 此外, 穿黄工程前与工程后的浮游植物细胞密度存在显著不同, 与 中线干渠原核微生物群落的研究结果类似 ${ }^{[20]}$, 这是穿黄工程长距离输水隧道的黑暗条件和较快流速导致 的, 可见,环境条件是空间分布的重要影响因素. 本研究发现, 硅藻在中线干渠沿程的细胞密度显著增加, 这 与干渠的水体环境有关, 夏季 $\mathrm{NO}_{3}^{-}-\mathrm{N}$ 浓度波动性增加, 浮游植物细胞密度与 $\mathrm{NO}_{3}^{-}-\mathrm{N}$ 浓度呈显著负相关, 秋 季 $\mathrm{PO}_{4}^{3-}-\mathrm{P}$ 浓度缓慢增加, 浮游植物细胞密度与 $\mathrm{PO}_{4}^{3-}-\mathrm{P}$ 浓度呈显著负相关, 冬季 $\mathrm{PO}_{4}^{3-}-\mathrm{P}$ 浓度沿程增加明显, Chl. $a$ 与 $\mathrm{PO}_{4}^{3-}-\mathrm{P}$ 浓度呈显著负相关. 此外, 浮游植物细胞密度和 Chl. $a$ 浓度的沿程增加与硅藻的生命代谢能 力和环境适应性有关: 在低光照或黑暗条件下, 硅藻可利用硝酸盐作为电子供体进行化能自养, 较蓝、绿藻 具有竞争优势, 恢复光照后可迅速恢复光合作用 ${ }^{[21]}$; 硅藻自身的特性赋予其在中线干渠的竞争优势, 使得它 的种类和数量较其他类群要多. 总体上, 中线干渠的浮游植物细胞密度和 Chl. $a$ 浓度沿程均有所增加, 说明 在输水过程不仅仅是藻类随水流的被动运输, 藻细胞在输移过程中有增殖生长行为存在, 氮、磷等为藻类的 生长提供了营养物质. 由此可见, 外部环境以及浮游植物自身的适应能力共同影响了群落的空间特征, 表现 为显著的空间异质性.

从 NMDS 与 ANOSIM 分析中 (图 7) 可以看出, 浮游植物群落结构变化的时间效应比空间效应更加明 显, 这可能是渠道内水体连通性以及快速流动导致的有效掺混削弱了空间距离对浮游植物群落组成的影 响,而南北两地的显著季节差异和温度特征对浮游植物群落的影响更明显.

\section{2 环境因子对浮游植物群落的影响}

大量研究表明, 水温、营养物质、水动力条件等多种因素可共同影响浮游植物群落的结构和功能 ${ }^{[22]}$; 南 水北调中线干渠作为输水渠道, 并不是天然河流, 调水过程每年按照相关计划进行, 不同时段的调水规程存 在差异, 本研究的全年监测数据经 $\mathrm{RDA}$ 与多元线性回归分析均确认水温、 $\mathrm{TP}$ 浓度、 $\mathrm{NH}_{3}-\mathrm{N}$ 浓度、流速和流量 是影响中线干渠浮游植物群落结构的重要因子, 该研究结果与以往其他水体的研究类似, 说明中线干渠具 有某些自然水体的属性.

水温对浮游植物种类和季节变化的重要影响 ${ }^{[23]}$ 主要是由于浮游植物细胞的诸多代谢过程为酶促反应, 这些生化反应过程受酶活性的影响, 而温度对酶活性有决定作用. 水温升高加速藻类种群的生长增殖, 且不 同藻类在水温适应性上存在物种差异, 这导致优势种随着水温变化而变化, 水温通过调控细胞活性近而成 为浮游植物群落结构变化的主要控制因子 ${ }^{[24]}$. 研究表明蓝、绿藻的最适温度要高于硅、隐藻 ${ }^{[23]}$. 本研究中干 渠水温为 $5.10 \sim 34.30^{\circ} \mathrm{C}$, 四季变化明显且存在显著差异, $\mathrm{RDA}$ 结果显示水温是影响群落结构的关键因子, 多 元线性回归分析显示水温与硅藻的相对丰度呈显著负相关, 与蓝藻、绿藻的细胞密度呈显著正相关, 低温条 
件下, 蓝绿藻相对丰度下降, 硅藻相对丰度占据优势. 如空星藻的最适生长温度为 $30 \sim 35^{\circ} \mathrm{C}^{[25]}$, 干渠夏季水 温较高, 适合空星藻生长, 因此它是夏季的优势种之一; 隐藻常被认为在水温较低时种群密度较高 ${ }^{[26]}$, 干渠 冬、春季水温较低, 这使得隐藻成为冬、春季的优势种. 因此水温影响和决定着干渠浮游植物细胞密度以及 优势类群的演变.

营养物质是浮游植物生长繁殖必需的, 也是浮游植物季节变化的重要环境影响因素 ${ }^{[27]}$. TN、TP 是影响 浮游植物细胞密度和群落结构的重要因子, 有研究显示早春时节藻类大量增殖的原因主要是对氮的快速吸 收利用 ${ }^{[22]}$; 本研究也显示 $\mathrm{NH}_{3}-\mathrm{N}$ 浓度与细胞密度呈显著负相关, 表明浮游植物生长会消耗大量 $\mathrm{NH}_{3}-\mathrm{N}$. 同 时, 由于硅藻生长的最适磷浓度较低 $(0.002 \sim 0.01 \mathrm{mg} / \mathrm{L})$, 随着水体中磷浓度的降低, 蓝、绿藻相对丰度降 低, 硅藻逐渐占据优势 ${ }^{[28]}$. 干渠 $\mathrm{TN}$ 浓度为 $0.39 \sim 2.13 \mathrm{mg} / \mathrm{L}$, TP 浓度为 $0 \sim 0.01 \mathrm{mg} / \mathrm{L}$, 氮浓度高, 磷浓度较 低, N/P 比值远大于 16 , 表现为磷限制, 这种营养条件更适合硅藻的生长.

流量、流速可显著影响藻类群落组成以及优势类群的演变 ${ }^{[29]}$. 一般来说, 蓝藻和绿藻较适合在静止或 弱紊动水体中生长, 硅藻在流动或紊动环境下可获得较大的增殖优势 ${ }^{[30]}$. 中线干渠水体持续流动高度掺 混, 流速范围为 $0.1 \sim 2.4 \mathrm{~m} / \mathrm{s}$, 平均流速为 $0.95 \mathrm{~m} / \mathrm{s}$, 相比较于其他水体流速较大 ${ }^{[31]}$. 本研究中, 蓝藻、绿藻的 细胞密度与流速呈显著负相关, 硅藻的相对丰度与流速呈正相关, 在中线干渠这种动态混合良好的生境中, 高流速使得硅藻的优势地位增强, 环境过滤与适者生存的选择作用更利于硅藻的增殖, 特别是那些比表面 积大且对低光有适应性的硅藻, 如桥弯藻、舟形藻、曲丝藻等 ${ }^{[32]}$. 极小曲丝藻具有良好的环境适应性, 易在 高流速水体中成为优势类群 ${ }^{[33]}$, 因此, 它成为中线干渠的全年优势种. 本研究结果显示, 流量与硅藻、绿藻 的细胞密度呈显著负相关, 流量加大可能会对水体中藻类密度具有一定的稀释作用. 对西江下游浮游植物 的研究也表明, 流量加大有利于种类丰富度的增加, 但不利于细胞密度的增加 ${ }^{[34]}$. 可见, 流量加大在一定程 度上可以改变藻类细胞密度, 杜绝大量藻类短时间内快速生长增殖或衰老死亡对水体营养盐的急剧影响并 可能导致水体异味物质含量升高等问题,可保障水质的稳定.

此外, 干渠沿线水工结构众多, 具备开展调度控藻的基础条件, 可通过优化运行管理调控水动力条件, 破坏藻类突发性大量增殖的必需条件, 从而有效防控藻类大量增殖. 有研究确认, 流速、流量等水动力条件 的改变, 可以影响营养盐在水体的时空分布, 改变藻类生长与营养盐间的动态响应关系 ${ }^{[35]}$, 对藻类大量快速 增殖起到抑制作用 ${ }^{[36]}$, 并减少水质安全问题发生的可能性. 本研究中, 西黑山分水口至团城湖呈现低流量 与低流速的特征, 细胞密度与 TN 浓度存在正相关关系且细胞密度较高, 基于前人的工作成果和本研究的相 关结果, 可以通过改变流速流量来达到 TN 浓度与藻细胞密度降低的目的. 陶岔渠首、穿黄工程南岸与穿黄 工程北岸均呈现高流速的特征, 藻密度与 $\mathrm{PO}_{4}^{3-}-\mathrm{P}$ 浓度呈显著正相关 $(P<0.05)$, 可以通过改变流速流量达到 降低 $\mathrm{PO}_{4}^{3-}-\mathrm{P}$ 浓度进而降低藻细胞密度的目的. 优势种与环境因子的相关性分析结果也显示: 春、夏季微囊 藻、极小曲丝藻细胞密度与流量呈显著负相关 $(P<0.05)$, 且在古运河暗渠、西黑山与惠南庄处细胞密度具有 较高值, 春、夏季空星藻细胞密度与流速呈显著负相关, 且在沙河渡槽与鲁山落地槽流处细胞密度具有较低 值, 因此可通过提高流量与流速, 对优势种的增殖进行控制.

可见, 通过生态调度调控浮游植物群落并协调水资源利用和生态环境的保护具有实施可行性, 因此在 后续研究中, 不仅要关注营养盐水平的变化, 更要充分考虑水动力条件改变对水质和浮游植物群落带来的 影响, 加强对生态调度的研究.

致谢: 感谢南水北调中线管理局鲁山管理处为本研究提供的大力协助和支持.

\section{4 参考文献}

[ 1 ] Liu CQ, Liu LS, Shen HT. Seasonal variations of phytoplankton community structure in relation to physico-chemical factors in Lake Baiyangdian, China. Procedia Environmental Sciences, 2010, 2: 1622-1631. DOI: 10. 1016/j. proenv. 2010. 10.173 .

[ 2 ] Becker V, Caputo L, Ordóñez J et al. Driving factors of the phytoplankton functional groups in a deep Mediterranean reservoir. Water Research, 2010, 44(11) : 3345-3354. DOI: 10.1016/j.watres.2010.03.018.

[ 3 ] Vogt RJ, Sharma S, Leavitt PR. Decadal regulation of phytoplankton abundance and water clarity in a large continental reservoir by climatic, hydrologic and trophic processes. Journal of Great Lakes Research, 2015, 41 : 81-90. DOI: 10.1016/ 
j.jglr.2014.11.007.

[ 4 ] van Gremberghe I, van Wichelen J, van der Gucht K et al. Covariation between zooplankton community composition and cyanobacterial community dynamics in Lake Blaarmeersen (Belgium). FEMS Microbiology Ecology, 2008, 63(2) : 222237. DOI: 10.1111/j.1574-6941.2007.00422.x.

[ 5 ] Wang YH, Chen L, Niu Y et al. Spatio-temporal variation in phytoplankton community and its influencing factors in Danjiangkou Reservoir. J Lake Sci, 2016, 28(5) : 1057-1065. DOI: 10.18307/2016.0516. [王英华, 陈雷, 牛远等. 丹江 口水库浮游植物时空变化特征. 湖泊科学, 2016, 28(5): 1057-1065.]

[ 6 ] Zhu KX. Phytoplankton community dynamics and eutrophication in the Three Gorges Reservoir [Dissertation]. Wuhan: Institute of Hydrobiology, Chinese Academy of Sciences, 2013. [ 朱孔贤. 三峡水库浮游植物群落动态与富营养化研究 [学位论文]. 武汉: 中国科学院水生生物研究所, 2013.]

[ 7 ] Liang JK, Xin XK, Lu L et al. Analysis of water quality variation and potential pollution sources in main channel of Middle Route Project of South to North Water Diversion. Yangtze River, 2017, 48(15):6-9, 61. [梁建奎, 辛小康, 卢路等. 南 水北调中线总干渠水质变化趋势及污染源分析. 人民长江, 2017, 48(15): 6-9,61.]

[ 8 ] Li YX, Zhang NQ, Li YY et al. Study on phytoplankton and evaluation of water quality in water source area of Middle Line Project of Transferring Water from South to North. J Lake Sci, 2005, 17(3) : 219-225. DOI: 10.18307/2005.0305. [李 运贤, 张乃群, 李玉英等. 南水北调中线水源区浮游植物. 湖泊科学, 2005, 17(3) : 219-225.]

[ 9 ] Jia HY, Xu JF, Lei JS. Relationship of community structure of phytoplankton and environmental factors in Danjiangkou Reservoir bay. Yangtze River, 2019, 50(5): 52-58. [贾海燕, 徐建锋, 雷俊山. 丹江口库湾浮游植物群落与环境因 子关系研究. 人民长江, $2019, \mathbf{5 0}(5): 52-58$. ]

[10] Editorial Board of “Methods for monitoring and analysis of water and wastewater”, State Environmental Protection Administration of China ed. Methods for monitoring and analysis of water and wastewater: fourth edition. Beijing: China Environmental Sciences Press, 2002: 243-285. [ 国家环境保护总局《水和废水监测分析方法》. 水和废水监测分析方法: 第 四版. 北京: 中国环境科学出版社, 2002: 243-285.]

[11] Zhang ZS, Huang XF eds. Freshwater plankton research method. Beijing: Science Press, 1991. [章宗涉, 黄祥飞. 淡水 浮游生物研究法. 北京: 科学出版社, 1991.]

[12] Hu HG, Wei YX eds. Chinese freshwater algae-Systems, classification and ecology. Beijing: Science Press, 2006. [胡 鸿钧, 魏印心. 中国淡水藻类——系统, 分类及生态. 北京: 科学出版社, 2006.]

[13] Hao YY, Sun GJ, Zhang LX et al. Relationship between community characteristics of the phytoplankton and environmental factors in Heihe River basin. J Lake Sci, 2014, 26(1) : 121-130. DOI: 10.18307/2014.0115. [郝媛媛, 孙国钧, 张立 勋等. 黑河流域浮游植物群落特征与环境因子的关系. 湖泊科学, 2014, 26(1): 121-130.]

[14] ter Braak CJF, Šmilauer P. CANOCO reference manual and CanoDraw for windows user's guide: Software for canonical community ordination (version 4.5). New York: Section on Permutation Methods Microcomputer Power, 200.

[15] Chen KN, Zhou WP, Bao CH et al. Response of phytoplankton to ecological restoration in eutrophic lakes: An experimental large enclosure in Wuli Lake, Lake Taihu. J Lake Sci, 2007, 19(4) : 359-366. DOI: 10.18307/2007.0402. [ 陈开 宁, 周万平, 鲍传和等. 浮游植物对湖泊水体生态重建的响应一以太湖五里湖大型围隔示范工程为例. 湖泊科 学, 2007, 19(4) : 359-366.]

[16] Da WY, Zhu GW, Wu ZX et al. Long-term variation of phytoplankton community and driving factors in Qiandaohu Reservoir, southeast China. J Lake Sci, 2019, 31(5) : 1320-1333. DOI : 10.18307/2019.0522. [笪文怡, 朱广伟, 吴志旭 等. 2002-2017 年千岛湖浮游植物群落结构变化及其影响因素. 湖泊科学, 2019, 31(5): 1320-1333.]

[17] Sheng HY, Yu ZM, Han YC et al. Phytoplankton community and its relationship with environmental factors of a large riverine reservoir, Fuchunjiang Reservoir in subtropical China. J Lake Sci, 2010, 22(2) : 235-243. DOI : 10.18307/2010. 0213. [ 盛海燕, 虞左明, 韩轶才等. 亚热带大型河流型水库一一富春江水库浮游植物群落及其与环境因子的关 系. 湖泊科学, $2010,22(2): 235-243$.]

[18] Yang SQ, Zu TX, Wang HB et al. Relationship between the structure of phytoplankton community and environmental factors in the Zhangye section of Heihe River. J Lake Sci, 2019, 31(1) : 159-170. DOI: 10.18307/2019.0115. [杨宋琪, 祖廷勋, 王怀斌等. 黑河张掖段浮游植物群落结构及其与环境因子的关系. 湖泊科学, 2019, 31(1) : 159-170.]

[19] Xu YG, Li AJ, Qin JH et al. Seasonal patterns of water quality and phytoplankton dynamics in surface waters in Guangzhou and Foshan, China. Science of the Total Environment, 2017, 590/591: 361-369. DOI: 10.1016/j. scitotenv.2017. 02.032 . 
[20] Luo ZX, Li SJ, Hou K et al. Spatial and seasonal bacterioplankton community dynamics in the main channel of the Middle Route of South-to-North Water Diversion Project. Research in Microbiology, 2019, 170 ( 1 ) : 24-34. DOI: 10.1016/j. resmic.2018.08.004.

[21] Kennedy F, Martin A, Bowman JP et al. Dark metabolism: A molecular insight into how the Antarctic sea-ice diatom Fragilariopsis cylindrus survives long-term darkness. The New Phytologist, 2019, 223 (2) : 675-691. DOI: 10.1111/ nph.15843.

[22] Wu L, Yu YH, Zhang TL et al. PCR-DGGE fingerprinting analysis of plankton communities and its relationship to lake trophic status. International Review of Hydrobiology, 2009, 94(5) : 528-541. DOI: 10.1002/iroh.200911129.

[23] Trombetta T, Vidussi F, Mas S et al. Water temperature drives phytoplankton blooms in coastal waters. PLoS One, 2019, 14(4) : e0214933. DOI: 10.1371/journal.pone.0214933.

[24] Sun X, Zhu GW, Yang WB et al. Spatio-temporal variations in phytoplankton community in Shahe Reservoir, Tianmuhu, China. Environmental Science, 2017, 38(10) : 4160-4168. DOI: 10.13227/j.hjkx.201704161. [孙祥, 朱广伟, 杨文斌 等. 天目湖沙河水库浮游植物群落结构的时空异质性. 环境科学, 2017, 38(10): 4160-4168.]

[25] Yan JQ, Huang XX, Tao Y et al. Suitable temperature and light intensity for culturing five species of freshwater microalgae. Chinese Journal of Ecology, 2012, 31(5) : 1104-1110. DOI: 10.13292/j.1000-4890.2012.0161. [严佳琦, 黄旭 雄, 陶妍等. 五种淡水微藻的适宜培养温度和光照强度. 生态学杂志, 2012, 31(5): 1104-1110. ]

[26] Barlow SB, Kugrens P. Cryptomonads from the Salton Sea, California. Hydrobiologia, 2002, 473 (1) : 129-137. DOI: 10. 1023/a: 1016585818665.

[27] Ma Y, Li GB, Li J et al. Seasonal succession of phytoplankton community and its relationship with environmental factors of North Temperate Zone water of the Zhalong Wetland, in China. Ecotoxicology, 2014, 23(4) : 618-625. DOI: 10.1007/ s10646-014-1231-9.

[28] Yang W, Deng DG, Meng XL et al. Temporal and spatial variations of phytoplankton community structure in Lake Erhai, a Chinese plateau lake, with reference to environmental factors. Russian Journal of Ecology, 2019, 50(4) : 352-360. DOI: 10.1134/S1067413619040179.

[29] Wang M, Wu HJ, Ma JA. Causes and characteristics of the eutrophication in large reservoirs in the Yangtze Basin. Resources and Environment in the Yangtze Basin, 2004, 13(5): 477-481. [王孟, 邬红娟, 马经安. 长江流域大型水库富 营养化特征及成因分析. 长江流域资源与环境, 2004, 13(5): 477-481.]

[30] Li FP, Gao Y, Zhang HP et al. Simulation experiment on the effect of flow velocity on phytoplankton growth and composition. J Lake Sci, 2015, 27 (1) : 44-49. DOI: 10.18307/2015.0106. [李飞鹏, 高雅, 张海平等. 流速对浮游藻类生长 和种群变化影响的模拟试验. 湖泊科学, 2015, 27(1): 44-49.]

[31] Tian SM, Yang Y, Qiao YM et al. Temporal and spatial distribution of phytoplankton chlorophyll-a and its relationships with environmental factors in Dongjiang River, Pearl River basin. J Lake Sci, 2015, 27 (1) : 31-37. DOI: 10.18307/ 2015.0104. [田时弥, 杨扬, 乔永民等. 珠江流域东江干流浮游植物叶绿素 a 时空分布及与环境因子的关系. 湖泊 科学, 2015, 27(1): 31-37.]

[32] Yang L. Spatiotemporal succession of phytoplankton functional groups in Dianshan Lake and its relationship with environmental factors [Dissertation]. Shanghai: Shanghai Ocean University, 2018. [杨丽. 淀山湖浮游植物功能群的时空演替 特征及其与环境因子的关系 [学位论文]. 上海: 上海海洋大学, 2018.]

[33] Potapova M, Hamilton PB. Morphological and ecological variation within the Achnanthidium minutissimum (Bacillariophyceae) species complex. Journal of Phycology, 2007, 43(3) : 561-575. DOI: 10.1111/j.1529-8817.2007.00332.x.

[34] Wang C, Lai ZN, Li XH et al. Annual variation pattern of phytoplankton community at the downstream of Xijiang River. Acta Ecologica Sinica, 2013, 33(14) : 4398-4408. [王超, 赖子尼, 李新辉等. 西江下游浮游植物群落周年变化模 式. 生态学报, 2013, 33(14): 4398-4408.]

[35] Yang ZH, Yang SC, Li D et al. Numerical simulation of eutrophication and its test of ecological operation schedule in Xiaojiang River, the tributary of Three Gorges Reservoir. J Lake Sci, 2016, 28(4) : 755-764. DOI: 10.18307/2016.0408. [杨中华, 杨水草, 李丹等. 三峡水库支流小江富营养化模型构建及在水量调度控藻中的应用. 湖泊科学, 2016, 28(4): 755-764.]

[36] Kelly VJ. Influence of reservoirs on solute transport: A regional-scale approach. Hydrological Processes, 2001, 15(7): 1227-1249. DOI: 10.1002/hyp.211. 